\title{
A New Journal for the Torrid Zone
}

If you want something you never had before, you must do something you have never done before.

South African Proverb, per Nathan Hare (2002).

\begin{abstract}
Aims and Scope
A peer-reviewed premium quality e-journal, the Journal of Tropical Psychology has this rationale: While there continues to be argument as to how much climate change is due to human or corporate events, there is no disagreement that the earth is becoming warmer, leading to a climate with more moisture in the air, stronger storms, flooding, and a great change for all the inhabitants of the earth. To understand the psychology of our planetary future, we may access the psychologists of tropical climates who are already successful in their adaptation to a daily life in an environment we may all share eventually. To provide a vehicle for these psychologists can be a valuable service, particularly since psychological journal articles originating in Europe or the United States have long provided the bulk of scientific and professional publications. Yet there is very substantial psychological work being done in tropical zone countries and regions. A few journals, such as Australia's Psychological Science, or the regional online Journal of Pacific Rim Psychology, are examples. The Journal of Tropical Psychology is specifically circum-global and unites the rapidly growing torrid climaterelated nations around the earth in the development and sharing of their psychological discoveries.
\end{abstract}

Countries: 'Tropical countries are those that lie within the region that we call the tropics. The tropics is the zone between the Tropic of Cancer, the parallel of latitude at 230 North, and the Tropic of Capricorn, the parallel of latitude at $23^{\circ}$ South. Everywhere in the tropics is struck by the sun's perpendicular rays at noon on a minimum of one day in each year. At the very centre of the tropics lies the equator, a spot equidistant from the north and south poles. Many people associate tropical countries with a few islands and palm trees but in fact a large section of the world lies within the tropics. In the Western Hemisphere, tropical countries include Mexico, all of Central America, all of the Caribbean islands from just south of Nassau in the Bahamas, and the top half of South America, including Colombia, Ecuador, Peru, Bolivia, Colombia, Venezuela, Guyana, Suriname, French Guiana, as well as the northern portions of Chile, Argentina, Paraguay, and Brazil. In Africa, the only nations that cannot be called tropical countries are Morocco and Tunisia in the north and Lesotho and Swaziland in the south. All the rest lie either entirely, or at least partly, in the tropics. While no European countries are tropical countries, the Middle East has four tropical countries: Yemen, which is entirely in the tropics, and parts of Saudi Arabia, Oman, and United Arab Emirates. India, in southern Asia, lies mostly in the tropics, and all countries of Southeast Asia are tropical countries. Australia, Micronesia, the Marshall Islands, Kiribati, and most of the other island nations of Oceania in the South Pacific are tropical countries, as well.' (Answers.com, 2010).

Climates: In addition to the geographical limits of past designated tropical countries, the rapidly expanding 'Torrid Zone' (Harding, 2009) increasingly includes additional countries and neighboring areas where people experience the same tropical climate. These will also be considered.

\section{Summary objectives for this journal:}

- To disseminate progress in adaptation to the global expansion tropical climates.

- To share the full range of psychological progress in the growing tropical climate regions.

- To develop an international network of psychologists working in these regions.

\section{Acknowledgments}

Special recognition in the formation of this journal should go to Vice-Chancellor and President Sandra Harding (our journal's Muse) of Australia's James Cook University for her vision; to JCU Singapore leadership, particularly Det Fischer (our journal's Godfather), for financial impetus; to Stephen May (our journal's Publisher) and his staff at Australian Academic Press; to Associate Editor Ed Helmes and the volunteer experts on the Editorial Board, supported by Managing Editor Natasha Riard and Journal Intern Sarah Li Wai Suen.

\section{Robert F. Morgan, Editor}

\section{Reference}

Harding, S. (2009). Introduction, Torrid Zone Symposium, United Nations Youth Conference, Brisbane. 